\title{
Discursos e significados SOBRE AS PESSOAS COM DEFICIÊNCIAS NOS LIVROS DIDÁTICOS DE PORTUGUÊS: LIMITES NA COMUNICAÇÃO DE SENTIDOS E REPRESENTAÇÕES ACERCA DA DIFERENÇA
}

\author{
SpeECH ANd MEANING abOUt PEOPLE WITH DISABILITIES IN PORTUguese \\ LANGUAGE WORKBOOKS: LIMITS TO THE COMMUNICATION OF MEANINGS AND \\ REPRESENTATION OF DIFFERENCES
}

Alessandra Santana Soares eBARROS ${ }^{1}$

RESU M O: estetrabal ho resumiu os principais achados deuma pesquisa quemapeou os modos derepresentação da pessoa com deficiência nos livros didáticos de Língua Portuguesa das séries iniciais do ensino fundamental . A amostra foi composta por livros julgados eaprovados pelo Programa N acional do Livro Didático, edição 2007. A pesquisa, empreendida metodologicamenteatravés deanalisedeconteúdo eanálise de discurso, buscou responder em quemedida, ecom quelimites as pessoas com deficiências são consideradas exemplos deexpressão da diversidade humana - preocu pação recente das propostas pedagógicas atuais. Sendo as obras aprovadas pelo PNLD aquel as sobre as quais o MEC recomenda que os professores das escol as públicas exercitem suas escol has - a partir das peculiaridades regionais ede projetos político-pedagógicos, cumpriu-seconferir, através dos resultados desta pesquisa, se estas escol has, que assim disseminarão um modo comum de entender o papel do respeito à diferença, contemplam os interesses das pessoas deficientes.

PA LA V RA S-CH A V E: livro didático delíngua portuguesa; análise dediscurso; pessoa com deficiência; educação especial.

\begin{abstract}
A BSTRACT: this article summarizes the main findings of a research project that mapped the ways disabled peopleare represented in Portuguese Language workbooks used in elementary school in Brazil. The samples were books that were analyzed and approved by the $\mathrm{N}$ ational Program of Didactic Books, 2007 issue. The research, methodologically carried out by analyzing both content and discourse, attempted to answer how much and within what limits peoplewith disability are considered examples of human diversity - theultimate pedagogical proposal. The books approved by the PNLD (N ational Program of Didactic Books) are thosethe Ministry of Education suggests public school teachers to choose, taking into consideration regional peculiarities and the school's "political-pedagogic projects". The research aims meant to check if these choices are in agreement with the interest of people with disabilities, considering that they will disseminate a common discourse for understanding theaim of the respect for differences.
\end{abstract}

KEYWO RD S: didactic books; Portugueselanguage; disability; special education.

\section{As PESSOAS COM DEFICIÊNCIA E AS AGENDAS DE DIREITOS}

Ao longo da história das civilizações ocidentais, a atitudedas sociedades complexas frenteaos indivíduos deficientes vem setransformando. Originalmente destinados à segregação explícita através do extermínio ou do confinamento, o que setem, na contemporaneidade, são posturas que sealternam etensionam-se

\footnotetext{
${ }^{1}$ Mestreem Saúde Coletiva e doutora em A ntropología, Profā A djunta da Facul dade de Educação da U niversidadeFederal daBahia - FACED/ UFBA - - Salvador - BA - alssb@ufba.br
} 
simultaneamenteentre o assistencial ismo de cunho paternalista eo investimento nas potencial idades dessas pessoas através da educação e da reabilitação. É neste continuum de demandas mais atuais que se inscreve a questão dos direitos dos deficientes.

Há algo em torno de três décadas, as exigências no cumprimento dos direitos das minorias, de um modo geral, vêm se sofisticando, demodo que, hoje, os pleitos levantados em nome dessas categorias não podem prescindir daquilo que se denomina inclusão social.

Por inclusão social se entende o acesso pleno aos bens e serviços comunitários, o usufruto integral eincondicional das conquistas científicas, sociais e culturais da modernidade, bem como o favorecimento à participação e à representatividade políticas. No que tange aos deficientes, a inclusão social vem setraduzindo, então, basicamente, nas demandas por maior acessibilidadeurbana, pela adequação da escola regular aos alunos com deficiência e pela inserção competitiva das pessoas deficientes no mundo do trabal ho.

A urgência na inclusão social das minorias se aperfeiçoou quando ampliou a pauta de reivindicações no combateao preconceito de modo a identificar e eliminar mesmo as formas mais sutis de manifestação deste fenômeno. Esta medida vem se expressando, assim, dentre outras formas, na vigilância ao modo como a imagem de mulheres, de negros, de índios, por exemplo, éveiculada. Ou seja, em tornar evidente quais significados são evocados a partir da representação dessas pessoas, pelos meios de comunicação de massa, principalmente.

\section{Livros didÁticos, COMUNicAÇÃo e CULTURA}

A vigilância empregada no tratamento da imagem de pessoas que pertencem a mi norias pode se estender a diversos veículos da indústria cultural: filmes, telenovelas, comerciais para a tel evisão, publicidadeimpressa, matérias de jornal. Tanto quanto cada um destes veículos, os textos didáticos:

\section{[...] têm parcela de responsabilidade no desenvolvimento de padrões de comportamento, resultad o de determinadas representações da realidade. Elas podem contemplar, prestigiar e promover certos segmentos da sociedade em detrimento de outros, bem como escamotear aspectos da realidade. (PROGRAMA NACIONAL DO LIVRO DIDÁTICO, 2004c, p. 79)}

Se esta pesquisa se interessou, em especial, pelos livros didáticos isto se deu em função do próprio direcionamento oferecido pela nossa Política N acional de Direitos Humanos. Neste sentido, aqui no Brasil, documentos oficiais, como o texto do Programa $\mathrm{N}$ acional de $\mathrm{D}$ ireitos H umanos, do Ministério da Justiça, fazem constar, dentreas 518 propostas de ações governamentais, as seguintes:

[....] apoiar o processo de revisão dos livros didáticos de modo a resgatar a história ea contribuição dos afro-descendentes para a construção da identidade nacional [...] A poiar o processo de revisão dos livros didáticos de modo a 
resgatar a história ea contribuição dos povos indígenas para a construção da identidade nacional. (CANDAU, 2003, p. 164-166).

Tratam-se de recomendações que, na verdade, reiteram as medidas de contínua avaliação dos livros didáticos empreendidas, desde 1996, pelo Programa $\mathrm{N}$ acional do Livro D idático - o PNLD as quais, dessemodo, assinalam o estreitamento do diálogo entre setores da vida pública - educação ejustiça - que mantém, em comum, compromissos expressos na forma de políticas degoverno.

Em verdade, a centralidade do livro didático nas pesquisas que investigam a disseminação de estereótipos, clichês, lugares-comuns e valores depreciativos em torno de categorias de pessoas é datada, no Brasil, a partir da década desessenta.

[...] Estudos e investigações sobre a produção didática brasileira vinham, reiteradamente, desde meados da década de 1960, denunciando a falta de qualidade de parte significativa desses livros: seu caráter ideológico e discriminatório, sua desatualização, suas incorreções conceituais e suas insuficiências metodológicas. (BATISTA, 2003, p.28).

Partindo do pressuposto da relevância da escola em relação a outras agências socializadoras a reflexão acadêmica sobreo conteúdo dos livros didáticos já assinalava, na época, contribuições embrionárias às pautas atuais de reivindicações de direitos das minorias. O que se denominava crítica ideológica (N OSELLA, 1979) do conteúdo dos livros didáticos se voltava amplamente para afirmação do papel dereprodução social da escola e para a denúncia das relações de produção capitalista, perpassando relações degênero edeclasse, principal mente (FREITAG, 1989, p. 86). Mulheres, negros, o trabal hador das camadas popularese as crianças carentes eram, assim, al vos preferenciais (FREITAG, 1989, p. 94)

Neste sentido, a presença do negro no livro didático foi, e ainda o é, fartamente explorada enquanto temática (ROSEM BERG, 1985; TRIUNPHO, 1987; PINTO, 1987; NEGRÃO, 1987; FIGUEIRA, 1990; PINTO; NEGRÃO, 1990; SANTOS, 1990; SILVA, 1995, 2001). Assim também, aquela sobreo índio (GUIM ARÃ ES, 1989; RODEGUERO, 1994; BARROS, 2000). Do mesmo modo, a pesquisa sobre a representação da mulher ou das relações de gênero nos livros didáticos demarcou o seu espaço (ROSEM BERG, 1987, 1989). O passar das décadas emprestaria uma abordagem mais fenomenológica no tratamento das representações sociais de categorias minoritárias nos livros didáticos, bem como uma ampliação no sentido deabarcar as pessoas com deficiências, iniciativas, então assumidas por Fagundes (1989), Cruz (1991), Piza (1991) eA maral (1992).

Em 1996, no bojo de uma ampla revisão acerca da qual idade editorial, a Política Nacional do Livro Didático através da seleção criteriosa dos livros que seriam adotados pelas escolas públicas, transformou aquelas preocupações em relação à imagem de grupos minoritários em medidas aplicadas de combate ao preconceito eà discriminação. 
Um dos critérios de avaliação desses livros pelo PNLD, é que o tratamento destinado aos diversos temas e assuntos, seja pela via dos textos, das atividades e mesmo das ilustrações, denote compromisso com um projeto amplo deconstrução da cidadania.

\begin{abstract}
[...] Embora partesignificativa dos critérios para essa aval iação decorresse das especificidades das áreas deconhecimento a queos livros didáticos se destinam, definiram-se, como critérios comuns de análise, a adequação didática e pedagógica, a qualidade editorial e gráfica, a pertinência do manual do professor para uma correta utilização do livro didático e para atual ização do docente. Definiu-se, ainda, então como critérios el iminatórios, que os livros: [...]; - não poderiam expressar preconceitos de origem, raça, sexo, cor, idade ou quaisquer outras formas de discriminação. (grifo meu). (BATISTA, 2003, p.30).
\end{abstract}

Nestesentido, énotável a ênfasequeo PN LD 2005 ofereceu ao aspecto da val orização da diversi dade, quando ilustrou a capa, de cada um dos guias de livros didáticos para as últimas séries do ensino fundamental, com crianças que representam grupos populacionais diversos. Assim, na capa do guia para Língua Portuguesa há uma menina negra, na capa do guia de Matemática há um garoto loiro, no de Geografia um jovem indígena, no deHistória uma menina branca eno deCiências há, justamente, uma menina com síndrome de Down.

Assim, pressupondo o respeito a amplas formas de expressão da diversidade, não apenas os negros, índios, ciganos ou mulheres, explicitamente colocados nas intenções das políticas, deveriam estar sendo objeto de atenção cuidadosa na veiculação de suas imagens e significados por parte dos conteúdos dos livros didáticos, como também, as pessoas com deficiências.

Não sesabe, entretanto, em queextensão estas medidas foram cumpridas. Pois, desde a edição dos critérios de aval iação do PN LD, à exceção do trabal ho de FIGUEIRA, 2000, em verdadeapenas um estudo derevisão querecapitulou trabal hos anteriores, não tem havido pesquisas que evidenciem os modos de representação das pessoas deficientes nos livros didáticos. Esta omissão é significativa se considerarmos que, desdea vigência da avaliação dequalidadedoslivros didáticos, a sociedadebrasileira vem experimentando um contexto deaumentada atenção no que tange aos direitos dos deficientes, em aspectos como a exigência de acesso ao ensino regular, a demanda pela garantia deprofissionalização, a edição demedidas legais deamparo como a pensão vitalícia (Benefício de Prestação Continuada) eas cotas para concorrência em concursos públicos. ${ }^{2}$

\footnotetext{
${ }^{2}$ Recentemente, uma pesquisa desteâmbito, aplicada a um meio de comunicação de massa, assinal ou uma iniciativa delevantamento dos significados simbólicos da deficiência, que se aproximou daquilo quesepoderia al cançar caso seinvestigasse o modo como, atualmente, num contexto de ampla afirmação da diversidade, as pessoas deficientes são representadas nos livros didáticos. A pesquisa (VIVA RTA , 2003) traçou o diagnóstico do comportamento editorial da imprensa brasileira quando os jornais trazem em pauta as questões da deficiência. Para compor esse retrato, foram analisadas 747 reportagens publicadas em 53 jornais detodo o Brasil, ao longo do ano de 2002.
} 
Tendo em conta o panorama então apresentado, foi empreendida uma pesquisa cujo objetivo era de descrever eanalisar o espaço e o formato que os livros

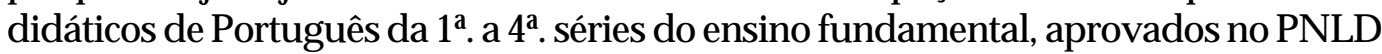
2007, ofereceram às pessoas com deficiência. Livros de Português são propícios para essas análises porque, em função de seus compromissos didático-metodológicos com o ensino/ aprendizagem, seapropriam denarrativas das mais variadas ordens: contos da tradição popular, composições infantis, histórias em quadrinhos, peças publicitárias, receitas da culinária, cartas, matérias dejornal, dentreoutras tantas. Essas narrativas diversas exemplificam as funções múltiplas da língua na intenção de contribuir para a formação de leitores que del a façam um uso tanto crítico como criativo. A mostras destes gêneros narrativos diversos são invariavelmente disponibilizadas sob o suporte da ilustração (CAMARGO, 1990). Assim, paraalém do fato de que um livro didático, de qualquer conteúdo curricular, requer que seu discurso explicativo esteja sustentado por gravuras edesenhos (dadaà inconsistência com a qual crianças dominam a língua escrita edada à dificuldadeem manter-Ihesa atenção concentrada em estímulos de uma única ordem) os livros de Português, destacáveis pelo apelo às tais narrativas demúltiplos gêneros, propiciam ainda mais a representação figurada de vários contextos designificação - das artes visuais, das ciências, da religião, da literatura, das conjunturas política eeconômica. Dessemodo, livros didáticos de Português, talvez mais do que outros, guardam amostras significativas, de valores eveícul os de nossa cultura.

\section{A PESQUISA}

Os livros analisados foram aqueles aprovados peloP rograma $\mathrm{N}$ acional do Livro Didático - PNLD, edição 2007, que compreendeu apenas os livros de 1a a $4^{a}$ séries do ensino fundamental. $\mathrm{O}$ acesso ao elenco das obras aprovados pela avaliação do MEC/ FNDE se deu através de consulta ao guia para o conteúdo curricular de Português, o qual, encaminhado às escolas públicas em meados desseano de2006, serviu de subsídio às decisões efetuadas pel os professores quanto às obras didáticas queesperam receber, em 2007, para distribuição gratuita aos alunos. (BRA SIL, 2006)

[...] Com base nos Guias, os professores teriam condições mais adequadas para a escol ha dos livros que julgavam mais apropriados a seus pressupostos, às características de seus alunos, às diretrizes do projeto político-pedagógico de sua escola. [...] Só não poderiam escol her livros que- em razão deapresentarem preconceito, discriminação, erro conceitual grave- foramexcluídos do Programa Nacional do Livro Didático. (BATISTA, 2003, p.32)

O processo de avaliação dos livros didáticos vem se aperfeiçoando a cada ano. Do mesmo modo, a cada ano que passa, a importância da garantia dos direitos decidadania das pessoas deficientes sefaz ouvir com mais evidência. Logo, escolher as últimas destas edições - a de 2007 - para analisar a presença e modos de representação da pessoa com deficiência foi uma maneira de fazer constar a maior atualidade possível nos resultados esperados. 
Assim, a partir da relação das coleções didáticas aprovadas, esta pesquisa prosseguiu no sentido da aquisição dos livros naversão livro-do-professor. Outro recortedefiniu, apenas, as editoras M oderna, Ática, Scipione, FTD, Saraiva e IBEP, tendo em vista o fato de terem sido estas as editoras, cujos livros foram solicitados em maior quantidade pel os professores das escolas públicas, segundo dados do FNDE para os PN LEM 2005 e2006. ${ }^{3}$

\subsection{A ferramenta crítica: a Análise de Discurso}

Um livro didático é marcadamente distinguível de outras produções literárias porque está voltado, prioritariamente, para o ensino ea aprendizagem, no decurso de um tempo "Ietivo" estabelecido. Por isso, busca adequar as complexidades das narrativas, em geral curtas, ao estágio de desenvolvimento intelectual do público-alvo, sem perder de vista o papel da oferta progressiva de tarefas sucessivamente mais desafiadoras. Assim, expõe os assuntos por etapas, sintetiza a temática em títulos introdutórios eem palavras-chaves, faz recaptulações freqüentes dos conteúdos deaprendizagem em resumos eem exercícios, diversifica os métodos etécnicas e, acima detudo, explora exaustivamenteos recursos visuais de que dispõe: destaques com letras em negrito e/ ou em caixa alta, cores e contrastes, arranjo espacial de boxes e figuras na página do livro. Além disso, contextualiza as temáticas às real idades dos alunos, enfatiza curiosidades easpectos prosaicos eanedóticos.

Nesta pesquisa, a ferramenta metodológica que de se fez uso para o tratamento dos livros didáticos foi aA nálise de D iscurso. A mesma não só cumpreo que se espera de uma análise de conteúdo (a proposição do significado desta mensagem, através da decifração de seu código) como se mostra aberta aos determinantes sócio-históricos e, assim sendo, busca situar a interpretação dos textos efiguras deum livro à luz deinformações sobre sua confecção e veiculação (IÑIGUEZ, 2004). Dessemodo, além de buscar classificações semânticas, sintáticas e de análises lógicas do encadeamento das proposições (afirmações, declarações, juízos) podendo se chegar a tabulações e freqüências estatísticas das categorias elegidas, éconsiderado o contexto de elaboração dos livros analisados (GILL, 2004). Nestesentido, não houve como ignorar o fato dequeaqueles livros didáticos foram produzidos para atender às exigências deum edital prévio. Ou seja, mais que um compromisso genuíno com os rumos da educação no País, o que há por parte dos autores eeditoras éo interesse em aumentar suas chances deaprovação com vistas a manterem-se no mercado disputando uma fatia das cifras que representam mais da metade de todo o dinheiro movimentado com a venda de livros no Brasil. $\mathrm{Na}$ análise de discurso proposta, então, cada livro didático - com seus textos, ilustrações, projeto gráfico, atividades, exercícios, recomendações ao professor, ainda que tomados em unidade - não foi tratado como um objeto lingüístico

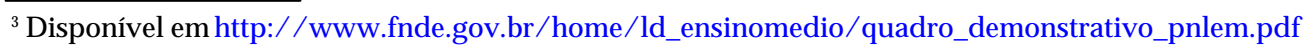


fechado, independente de sua produção e recepção. Reitera-se, ainda, que o que se analisou foi o conjunto dos vários recursos expressivos de cada livro. Isto é importante ao se tomar um livro didático como objeto de análise, uma vez que uma característica marcante destetipo delivro éancorar as narrativas escritas nas ilustrações (CAMARGO, 1990).

Dadas estas considerações teórico-metodológicas, procedeu-se à contagem do número de vezes, que, em cada um dos livros, apareciam pessoas com deficiência em ilustrações ou em menções no corpo dos textos escritos. Para fins de quantificação, foram consideradas como inserções válidas tanto a reprodução defiguras, fotos, gravuras, desenhos depessoas- crianças, adolescentes ou adultos - com deficiências, quanto os recursos e acessórios de que fazem uso e que, portanto, simbolizam essa condição: muletas, cadeiras de rodas, bengalas, mãos sinalizando o al fabeto de sinais. Considerou-se, na coleta de dados, aquelas inserções cuja referência fosse direta eimediatamente dirigida à deficiência, como também aquel as que, mais uma vez, simbolizassem a condiç̧ão de deficiência, a exemplo das placas desinalização urbana que contêm a figura de uma cadeira de rodas. Os textos escritos foram considerados em quaisquer gêneros narrativos, nos quais se identificassem os termos: deficientefísico, deficientemental, deficiente visual, deficienteauditivo, cego, surdo, aleijado, portador denecessidades especiais, criança excepcional, síndrome deDown. A figura folclórica do Saci-Pererênão foi contemplada como uma representação válida (da deficiência física, no caso), exceto naquelas situações em que houvesse sido, de antemão, referenciada como tal expressamente pelo livro didático.

De posse dessas prerrogativas analíticas, seconstruiu um instrumento de suporte à coleta de dados que classificou inicial mente o número de inserções das deficiências por tipos. Em que peseo fato da classificação das deficiências em apenas quatro tipos - deficiência física, deficiência mental, deficiência visual, deficiência auditiva - ser reducionista, para fins deanálise, foi esta categorização da qual a pesquisa se valeu. Essa decisão considerou que são essas denominações, nesse espectro de variação, aquelas apreendidas pelos autores dos livros que almejam atingir um público (alunos e professores) o qual é leigo no tocante a especificidades nomenclaturais acerca da deficiência. Ao mesmo tempo, na elaboração do instrumento, buscou-se associar as referências textuais (tomando aqui o sentido detexto numa perspectiva ampliada quecontempla tanto narrativas verbais/ escritas, quanto iconográficas) aos seus contextos derelação. Assim sendo, foram quantificadas as inserções que evocassem a imagem da pessoa com deficiência em três categorias de circunstância, convencionadas a seguir.

1) Aparições incidentais: tidas como aquelas gratuitas, ou seja, que aparecem "disfarçadamente" em meio aos demais recursos didáticos nas páginas de um livro. Foram assim entendidas porque compõem o conjunto das gravuras, ou dos textos de leitura, sem que se espere que sirvam de apoio necessário à discussão subjacente à unidade temática do livro, e menos ainda, a um 
questionamento sobre a condição de deficiência. Passam quase despercebidas e sua qualidade sutil é, possivelmente, a força diferencial de uma possível mensagem em favor da positivação da imagem da pessoa com deficiência. Estas inserções só foram consideradas efetivamente incidentais quando distanciadas dequal quer referênciaà diversidadeda condição humana. Assim, por exemplo, uma gravura queilustrasse um grupo decrianças marcadamente distinguíveis umas das outras, pela cor da pele e/ ou traços étnicos, eque no meio dessas se postasse uma outra, digamos, em cadeira de rodas, não seria tida como uma inserção categorizável como aparição incidental . As aparições verdadeiramente incidentais eram aquelas cuja referência à condição de deficiência não era retomada nas recomendações constantes no manual do professor, de sorte que não havia sugestões, acessórias àquelas próprias à temática da unidade, decomo, aproveitand o o ensejo, se poderia debater com as crianças a questão dos direitos das pessoas deficientes, por exemplo.

2) Aparições propositais: tidas como aquelas relacionadas ao tópico específico, objeto da unidade ou capítulo do livro. Para atender as recomendações do MEC, o tratamento transversal dos conteúdos em temáticas contemporâneas ederelevância - como a pluralidadecultural, a saúdeeo meio ambiente- tem sido a tônica das propostas didático-metodológicas da maior partedas editoras. Por isso, émuito comum seencontrar, mesmo nos livros de Língua Portuguesa, capítulos ou unidades inteiramente destinadas à questão do direito à diversidade ou à importância de hábitos saudáveis de higiene e nutrição. Nessas situações, discutir a temática da tolerância frente à diferença, por exemplo, é o foco de atenção primário e é, nesse sentido, que se abre espaço para fazer constar uma matéria dejornal que relate, por exemplo, a história de vida de uma criança cega ou, ainda, uma peça publicitária que reclamea oferta de solidariedade para com portadores da síndrome da talidomida. Exercícios de interpretação de textos, ortografia, sintaxe eoutros, vem, então a reboque do tema gerador da unidade. Há livros ainda que, embora não tendo destinado espaços bem definidos para temas que promovam a formação cidadã dos alunos, demonstram a preocupação em não ignorar essas temáticas. Assim o fazem quando, por exemplo, ilustram "casual mente" uma cena, de uma unidade temática qualquer, com crianças negras, indígenas, brancas, japonesas, convivendo em harmonia. Segundo os pressupostos analíticos estabelecidos para essa pesquisa, se porventura, em meio àquelas crianças uma estivesse em cadeira de rodas, o tipo de inserção de imagem da pessoa com deficiência seria, então, categorizável como proposital.

3) Aparições instrumentais: os livros de Português afirmam a necessidade do trabalho didático com múltiplos códigos e diversas possibilidades de comunicação de sentidos e, assim sendo, frequentemente retomam a importância do respeito aos regional ismos, à norma não culta, e aos dial etos como formas de expressão da diversidade lingüística humana. Logo, essa terceira categoria, que circunstanciou a identificação de representações de 
pessoas com deficiência nos livros didáticos de Língua Portuguesa, diz respeito àquelas imagens - ilustrações ou narrativas textuais - cuja finalidade primeira é explanar os usos da língua e/ ou a função da linguagem. São inserções próprias àqueles capítulos ou unidades temáticas denominadas, por exemplo, como "Mensagensemensageiros" ou "Meios deComunicação", nos quais a função representativa da linguagem é apresentada nas possibilidades de expressão da Língua de Sinais, das placas de trânsito, do al fabeto Braille, do código Morse.

\section{Resultados e discussão}

A pesquisa queesteartigo relata analisou 26 coleções delivros didáticos de língua portuguesa. (O universo total dos livros de português aprovados pelo PN LD 2007 compreende 36 coleções. A diferença entre este universo ea amostra estudada correspondeàquel es títulos de editoras de menor expressão no mercado editorial, bem como, a três coleções, de uma grande editora, quenão puderam ser adquiridas em função de falta de estoque). Chamam-se coleções, porque cada autor/ editora deve, necessariamente, submeter à avaliação do MEC o conjunto dos quatro livros - um para cada série dos anos iniciais do ensino fundamental. Desse modo, cada livro foi apreciado no contexto da coleção a que pertencia, ou seja, relativamente aos demais livros das séries iniciais daquele mesmo autor/ editora. Contudo, a quantificação equal ificação dos achad os remeteram-se a cada um dos livros, individualmente.

A ssim sendo, as 26 coleções levaram à análise de 104 livros de língua portuguesa para as quatro primeiras séries do ensino fundamental , que deverão estar em circulação nas escolas públicas, no ano de 2007. Em vintee seis destes 104 livros há menções expressas ou indiretas à problemática da pessoa com deficiência, o que representa $25 \%$ da amostra. Pensar esta percentagem em termos devalidade ou eficácia do ponto de vista da representatividade que uma minoria reclama no imaginário social é um empreendimento de propósito e pressupostos duvidosos. Um meio de comunicação não éum espel ho que possa refletir demodo imediato e unívoco os valores, concepções ou representações de uma coletividade. Assim, pois, livros didáticos não são, necessariamente, repositórios privilegiados de imagens a partir do qual coletividades constroem suas visões de mundo. Uma possibilidadeanalítica seria buscar correspondência entre este percentual de $25 \%$ eas estatísticas que situam as pessoas com deficiências em relação ao universo da população brasileira. O censo do ano de 2000 a quantificou em 14,5\% (IBGE, 2001). Um estudo quesugere uma flexibilização no modo deinterpretar esse percentual, a partir da supressão das dificuldades funcionais próprias do envelhecimento, propôs uma leitura de 2,5\% da população brasileira como portadora dealgum tipo de deficiência (NERI, 2003). A inda que se superasse essa divergência estatística, não seria possível, por razões de ordem interpretativa, transpor a barreira que se interpõe entre duas instâncias então, praticamenteincomensuráveis - a realidade 
factual e quantitativa de manifestação da deficiência e o plano da percepção coletiva que se tem, ou que se quer ter, dela.

A militância em defesa dos direitos de minorias tem apontado sugestões numéricas para a partici pação equânime das pessoas que representam as várias etnias nos meios de comunicação, de tal sorte que, a visibilidade alcançada por negros eíndios nos livros didáticos analisados éexpressiva epatente. Logo, esses achados de inserções imagéticas - textuais, pictóricas - de pessoas com deficiência em $1 / 4$ dos livros didáticos de português do ensino fundamental devem ser enxergados num contexto de massiva afirmação da diversidadeétnicoracial , pois praticamente todos os livros anal isados continham al guma apreensão de sentidos em favor da imagem de crianças negras e índias.

Nestes livros que destinaram algum espaço para representarem a imagem da pessoa com deficiência, foram identificadas três inserções relativas à deficiência mental, 30 inserções relativas à deficiência física, 7 inserções relativas à deficiência visual e 5 inserções rel ativas à deficiência auditiva.

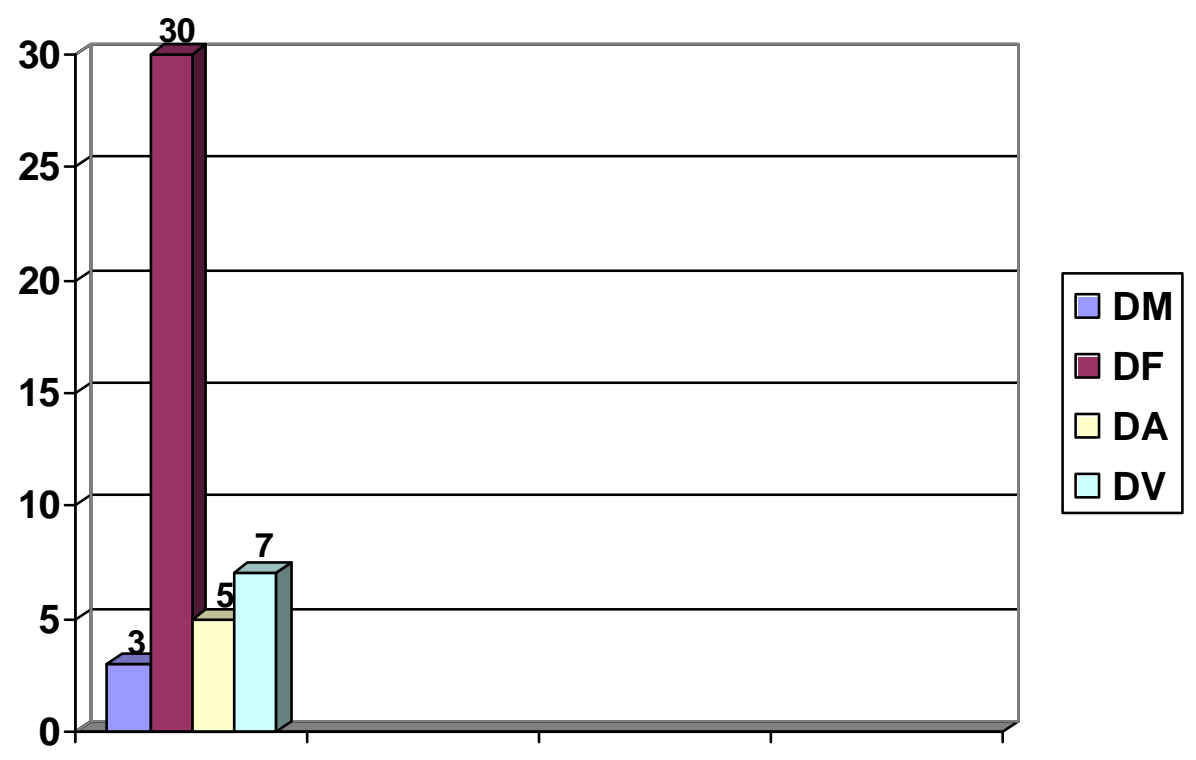

Figura 1- Representatividade da deficiência nos livros didáticos de Português da 1a a 4⿳亠丷厂 séries, por números absolutos, deinserções narrativas textuais ou pictóricas. (DM = inserções relativas à deficiência mental; $D F=$ relativas à deficiência física; $\mathrm{DA}=$ relativas à deficiência auditiva; $\mathrm{DV}=$ rel ativas à deficiência visual .) 


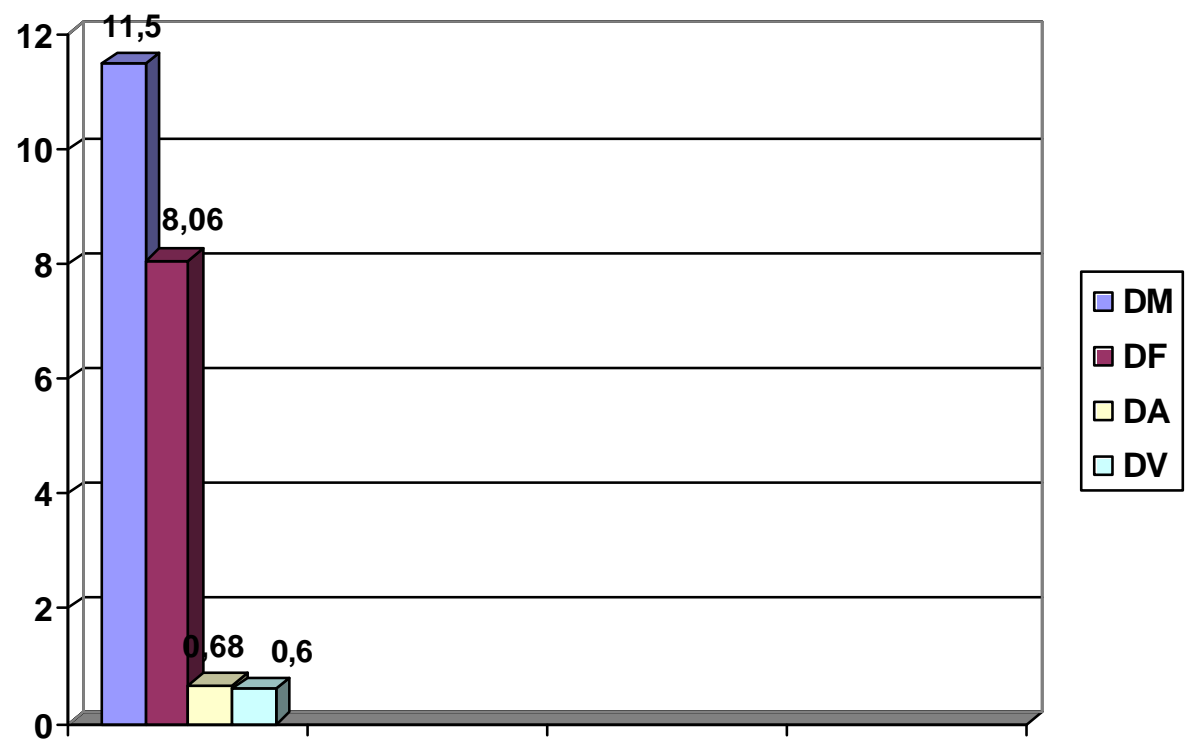

Figura 2 - Prevalência, em percentuais, dos tipos de deficiências na população brasileira segundo o censo IBGE 2000. (Adaptado a partir da supressão das dificul dades funcionais próprias do envel hecimento, segundo NERI, 2003). Para o computo da Deficiência Física, foram consideradas as categorias tetraplegia, paraplegia, hemiplegia $(0,44 \%)+$ falta de um membro ou parte dele $(5,32 \%)+$ incapacidadedecaminhar (2,3\%).)

Este achado se faz bastante interessante se confrontado com as estatísticas quesituam a distribuição da deficiência, por diferentes tipos, no Brasil. A ssim vejamos: enquanto no universo da população brasileira recenseada no ano de 2000, a deficiência mais presente era a do tipo mental (fig. 2), éesta mesma - a deficiência mental - aquela que se faz menos representada nos livros didáticos analisados. Se consi derarmos ainda, queos censos anteriores - de 1981 e de 1991 a despeito das divergências nas sistemáticas de categorização dos tipos de deficiência, também posicionaram a deficiência mental como a mais prevalente (NERI, 2003), essa discrepância entre um objeto e sua representação, que esta pesquisa evidenciou, reclama de fato, maior atenção. A condição de deficiência, ampliada em seu conceito para a lém da perspectiva clínica que descreve sinais no corpo e quantifica incapacidades, requer que se incorporem as experiências dos sujeitos, os condicionantes sociais e econômicos e os limites operacionais das políticas deintervenção. Isto faz da deficiência, um objeto depesquisa, deprodução de conhecimento, de transformação de real idades, muito peculiar, no sentido de quecarrega uma subjetividadequeressignifica tanto a percepção individual, quanto coletiva de um fenômeno. O que haveria na deficiência física, que a leva a ser 
representada nos livros didáticos de uma maneira tal que não corresponde à realidadeepidemiológica de uma população? Talvez a facilidade desimbolizá-la quando para tanto basta uma cadeira de rodas como significante. N o entanto, não foi esta, curiosamentea apropriação do M inistério da Educação quando das últimas campanhas pela inclusão de crianças com deficiências no ensino regular. A do ano de2000, por exemplo, teve como íconea síndromede Down (BA RROS, 2005).

Então, resta pensar, talvez, que esta submissão do espectro das deficiências à deficiência do tipo físico seja, apenas, um desdobramento da percepção superficial quetem o senso comum acerca da dimensão da experiência da deficiência. Assim, não por acaso, foi possível identificar em algumas passagens dos livros didáticos analisados, trechos que, ao fazerem referência à deficiência, não eram capazes de abrangêla aos tipos visual eauditivo, mesmo quando, obrigatoriamente deveriam fazêlo. Ao mencionarem à proteção à criança deficiente, tendo como referência a Carta dos Direitos das Crianças, três livros reproduzem os direitos enumerados restringindo a proteção àquelas crianças que "tem al guma deficiência física ou mental" (CEREJA, 2004, p.205; GOMES, 2003, p.132; MARIN HO, 2001, p.45). Do mesmo modo, outro livro fala nas Para-olimpíadas como se no evento competissem apenas deficientes físicos ou mentais (CA VÈQUIA, 2001, p.87).

No tocante às categorias de circunstâncias em que estas inserções poderiam ser enquadradas, 9 foram aparições incidentais, 20 foram aparições propositais e 14 aparições instrumentais. São achados que evidenciam uma disposição deliberada dos autores/ editora em promover, junto às crianças, uma formação cidadã que incorpore questão dos direitos das pessoas com deficiência. Entretanto, esta categorização, por tipos de aparições, como era de se esperar, reproduziu a predominância da deficiência física, tanto no modo proposital quanto no modo incidental. Tal constatação, não só recapitula o contraste já designado entre a deficiência como um fato e a deficiência como uma possibilidade de representação, como, acima de tudo, permite afirmar mais categoricamente que um dos desdobramentos desse efeito de percepção, já assinalado, é a redução nominal - simbólica - do espectro das deficiências à deficiência física, apenas. Isto podeser afirmado, dentreoutras razões, em função da qualidadenão provocadora das aparições incidentais. Elas carregam a característica de impregnarem instantaneamente o imaginário do leitor - ao modo da propaganda sub-reptícia, sem que por outro lado, favoreçam qualquer espaço para reflexão crítica: a mensagem que trazem é, então, a que fica. A deficiência existe, e pronto. Que os modos da deficiência existir não se limitam àqueles próprios das pessoas que usam cadei ras derodas, haverá deser, sechegar a ser, uma consideração sempretardia.

As aparições instrumentais, por outro lado, estavam mais bem diluídas por entrea deficiência visual, a deficiência auditiva ea deficiência física. Contudo, no tocante a esse aspecto, o tratamento destinado à deficiência auditiva merece um destaque especial. Consi deremos, de antemão, o panorama de afirmação da importância da diversidade de códigos lingüísticos (dialetos, regionalismos, a 
norma não-culta) e degêneros discursivos (cartazes, peças publicitárias, histórias em quadrinhos, crônicas, poemas, matérias dejornal) sob o qual são apresentados os conteúdos eas atividades dos livros didáticos de português. É nesse panorama que estes livros assinal am a existência da Língua Brasileira de Sinais - LIBRAS como uma ferramenta de comuni cação para os deficientes auditivos. Entretanto, o tratamento destinado ao papel da língua de sinais na comunicação de sentidos entre as pessoas surdas acaba resvalando em superficialidades e equívocos. Os livros didáticos de português para as primeiras séries do ensino fundamental parecem não conhecer a complexidade da Língua deSinais, seu status lingüístico e a dimensão das suas possibilidades expressivas. Assim o fazem quando recorrentemente a designam simplesmente como um alfabeto manual. Essa designação ainda que não seja expressa nestes exatos termos é necessariamente assim interpretada, pois, as atividades e exercícios que são sugeridos pelos livros pedem, por exemplo, que os al unos construam frases ou que as traduzam a partir da ilustração seqüenciada das letras do alfabeto digital. Com isso, subtraem a qualidade original de sintaxe, gramática e ordenamento semântico da língua de sinais, reduzindo-a a uma reprodução imitativa da língua portuguesa. Incorrem num erro assinalado por REILY (2004, p. 119), como um dos tantos mitos que circulam acerca da Língua deSinais:

\begin{abstract}
[...] A datilologia (letras sinalizadas com as mãos) não deve ser confundida com a língua de sinais. A datilologia é um código, como o Braile. Para cada letra, um sinal. Não há margem para várias interpretações. Na língua desinais, no entanto, o sentido se constitui gramatical mente, na seqüência de sinais, considerando-se, também a expressão facial ecorporal.
\end{abstract}

Desse modo, alguns livros de português, três deles precisamente (FITTIPA LDI, 2004, p.58; ORCHIS, 2005, p.65; SOUZA , 2004, p.141), acabam por prestar um desserviço à missão de afirmar a importância do respeito à diversidade cultural apregoada, muitas vezes, nesses mesmos livros. Pois, desconsiderar a especificidade, que não é mera idiossincrasia, da língua de sinais é descuidar do papel que ela cumpre na constituição de valores para a comunidade surda, o que acaba representando, então, um descuido no quetange à importância da afirmação dos direitos das pessoas com deficiência auditiva. Segundo Skliar (2004, p. 102-103):

\footnotetext{
[...] A participação na comunidade surda se define pelo uso comum da língua de sinais, pelos sentimentos de identidade grupal, o autoconhecimento e identificação como surdo [...] A língua de sinais anula a deficiência e permite que os surdos consigam, então, uma comunidade lingüística minoritária diferente enão um desvio da normalidade.
}

Conclui-se, portanto, quea língua de sinais - característica edefinidora cultural das pessoas surdas - do modo como foi retratada em al guns livros didáticos deportuguês do ensino fundamental, acabou seprestando a reafirmar estereótipos. O desconhecimento das peculiaridades rel ativas à surdez eà comunidade surda, 
desdobrou-se, ainda, em um equívoco conceitual: fazer uso da denominação "surdo-mudo", (GREGOLIN, 2004, p.23; ALMEIDA, 2005, p.10) sendo que caberia simplesmente o termo "surdo". Mais que apenas um preciosismo nomenclatural, esse deslize reforça, no entender dos militantes que defendem os direitos da comunidade surda, e mesmo dos lingüistas que estudam a qualidade comunicativa da língua de sinais, a caricatura da pessoa surda como alguém absolutamente incapaz de se expressar (FELIPE, 2001).

\section{Considerações finais}

Esta pesquisa reconhececomo não esgotada a possibilidade deanálise frente ao objetivo pretendido. Assume o limite, todavia, exigido por um relato crítico que anseie apontar problemas relevantes e soluções realizáveis em tempo hábil. Logo, fica a titulo derecomendações, a confecção deerratas, endereçadas ao Guia do Livro Didático, PN LD 2007 - Língua Portuguesa, bem como àqueles livros por esteartigo assinalados, no intento deque se corrijam os equívocos cometidos. Fica ainda a sugestão da apreciação destes resultados pela Comissão Técnica de pareceristas eavaliadores - conteúdo curricular Língua Portuguesa-continuamente designada pelo M inistério da Educação para jul gamento dos livros tri anualmente inscritos no Programa Nacional do Livro Didático.

\section{ReferênCIAS}

ALMEIDA. P. N. Língua Portuguesa: 3ā série. São Paulo: Saraiva, 2005 (Coleção Leitura Expressão Participação).

AMARAL, L. A. Espelho convexo: o corpo desviante no imaginário coletivo, pela voz da literatura infanto-juvenil. 1992. Tese (Doutorado em Psicologia Social) - Instituto de Psicologia da USP, São Paulo, 1992.

BARROS, A. Alunos com deficiências nas escolas regulares: limites de um discurso. Saúde e Sociedade, v. 14, n.3, p.119-133, 2005.

BARROS, D. L. P. Esta é uma outra história: os índios nos livros didáticos de história do Brasil. In: BARROS, D. L. P. (Org.) 0 s discursos do descobrimento: 500 emais anos de discursos. São Paulo: EDUSP/ FAPESP, 2000.

BATISTA, A. A. G. A avaliação dos livros didáticos: para entender o Programa Nacional do Livro Didático (PNLD). In: ROJO, R.; BATISTA, A.A.G. (Org.) Livro D idático de Língua P ortuguesa, Letramento e Cultura Escrita. Campinas: Mercado das Letras, 2003. p. 25-68.

BRA SIL, Secretaria de Educação Básica. G uia do Livro D idático 2007: Língua Portuguesa: séries/ anos iniciais do ensino fundamental/ Secretaria de Educação Básica. Brasília: Ministério da Educação, Secretaria de Educação Básica, 2006.

CAMARGO, L. O papel da ilustração nos livros para crianças. Jornal da A lfabetizadora. Rio de Janeiro, n. 8, 1990.

CANDAU,V. M. (Coord.) Somos tod@s iguais? Escola, discriminação e educação em direitos humanos. Rio de Janeiro: DP\&A, 2003.

CAVÉQUIA, M. P. Português: 3a série. São Paulo: Scipione, 2001. (A escola é nossa). 
CEREJA, W. R. Português: linguagens. São Paulo: A tual, 2004. v. 2.

CRUZ, M. 0 deficienteeas difer enças na leitura infantil ejuvenil: bibliografia. São Paulo: Secretaria Municipal de Cultura de São Paulo - Seção de Bibliografia e Documentação, 1991.

FAGUNDES, V. A. Imagem social do "deficiente" nos livros didáticos do primeiro grau. 1989. Dissertação (M estrado em Psicologia Social ) - Pontifícia UniversidadeCatólica deSão Paulo, 1989.

FELIPE, T. A. Libras em contexto: curso básico, livro do professor instrutor. Brasília: Programa N acional de A poio à Educação dos Surdos, MEC: SEESP, 2001.

FIGUEIRA, E. As pessoas com deficiências no contexto da literatura infanto-juvenil e didática. M imesis, Bauru, v. 21, n.1, p. 39-52, 2000.

FIGUEIRA, V. M. O preconceito racial na escola. Estudos A fro-asiáticos, Rio de Janeiro, n.18, p.63-72, 1990.

FITTIPALDI, A. A legria de Saber: português, 2a série: ensino fundamental. São Paulo: Scipione, 2004 (Coleção A legria de Saber).

FREITAG, B.; COSTA, W.F.; MOTTA, V.R. O livro didático em questão. São Paulo: Cortez/ Autores A ssociados, 1989.

GILL, R. A nálise de Discurso. In: BAUER, M.W.; GASKELL, G. Pesquisa qualitativa com texto, imagem e som: um manual prático. 3. ed. Petrópolis: Vozes, 2004. p. 244-270.

GOMES, S. Língua Portuguesa, 4ạ série: ensino fundamental. São Paul o: IBEP, 2003. (Coleção Vitória Régia).

GREGOLIN , M. R. V. O s caminhos da Língua Portuguesa. 3. ed. São Paulo: A tual, 2004 (Coleção Os Caminhos). v. 3.

GUIMARÃES, T. M. 0 índio no livro didático. In: SEMINÁRIO LIVRO DIDÁTICO: a discriminação em questão, 2, Recife, 1988. A nais... Recife: Secretaria de Educação de Pernambuco, 1989. p. 47-54.

IÑ IGUEZ, L. Os fundamentos da análise de discurso. In: em Ciências Sociais. Petrópolis: Vozes, 2004.

INSTITUTO BRASILEIRO DE GEOGRAFIA E ESTATÍSTICA. Censo D emográfico 2000. Características Gerais da População. Resultados da A mostra. Brasília: IBGE, 2001

MARINHO, L. F. Língua Portuguesa: ensino fundamental: 4a série. São Paulo: Moderna, 2001

NEGRÃ O, E. V. A discriminação racial em livros didáticos e infanto-juvenis.Cadernos de Pesquisa, São Paulo, n. 63, p. 86-7, 1987.

NERI, M. et al. Retratos da D eficiência no Brasil (PPD). Rio de Janeiro: Fundação Getúlio Vargas/ IBRE, CPS, 2003.

NOSELLA, M. L. C. D. A s belas mentiras: a ideologia subjacente aos textos didáticos. São Paulo: Cortez/ Moraes, 1979.

ORCHIS, A.; CHU, A.; SIM ON CELLO, V. Língua Portuguesa: 1a série. São Paulo: FTD, 2005 (Coleção Registrando Descobertas).

PINTO, R. P. A representação do negro em livros didáticos de leitura. Cadernos de Pesquisa. São Paulo, n.63, p.88-92, 1987. 
PINTO, R.P.; NEGRÃO, E.V. D e ol ho no preconceito: guia para professores sobre racismo em livros para crianças. Textos FCC, n. 5. São Paulo: Fundação Carlos Chagas, 1990.

PIZA, E. Imagens da deficiência na literatura infanto-juvenil:vícios e usos. In.: CRUZ, M. 0 deficientee as diferenças na leitura infantil ejuvenil: bibliografia. São Paulo: SecretariaM unicipal de Cultura de São Paulo, Seção de Bibliografia e Documentação, 1991, p. 17-21.

PROGRAMA NACIONAL DO LIVRO DIDÁTICO. PNLD 2007. Língua Portuguesa. Guia de Livros Didáticos 1aa a 4a séries. Brasília: MEC, FNDE,2006

REILY, L. Escola Inclusiva: linguagem e mediação. Campinas: Papirus, 2004.

RODEGHERO, C. S. O índio no livro didático. In: MARCON, T. (Org.). História e cultura Kaingang no sul do Brasil. Passo Fundo, 1994, p. 229-254.

ROSEMBERG, F. A imagem da mulher no livro didático. SEMINÁRIO DO LIVRO DIDÁTICO: A discriminação em questão. A nais... Recife: Secretaria de Educação de Pernambuco, 1989

ROSEMBERG, F. Literatura Infantil e Ideologia. São Paulo: Global, 1985.

ROSEMBERG, F. O livro didático. Revista A nde, São Paulo, v. 1, n.1, p.37,1987.

SANTOS, J. F. A questão do negro na sala de aula. São Paulo: Ática, 1990.

SILVA, A. C. D esconstruindo a discriminação do negro no livro didático. Salvador: EDUFBA, 2001.

SILVA,A.C. A discriminação do negro no livro didático. Salvador: CEAO/ EDUFBA,1995.

SKLIAR, C. (Org.) Educação e Exclusão: abordagens sócio-antropológicas em Educação Especial. Porto Alegre: Mediação, 2004.

SOUZA, C. G.; MAZZIO, L. P. Língua Portuguesa: 2ª série. São Paulo: FTD/ Quinteto Editorial, 2004. (Coleção de Olho no Futuro).

TRIUNPHO,V. R. S. O negro no livro didático e a prática dos agentes de pastoral negros. Cadernos de Pesquisa. São Paulo, n.63, p.93-95,1987.

VIVARTA, V. M ídia e deficiência. Brasília: ANDI; Fundação Banco do Brasil, 2003. (Série Diversidade). 